MATEC Web of Conferences 19, 01001 (2014)

DOI: $10.1051 /$ matecconf/ 20141901001

(C) Owned by the authors, published by EDP Sciences, 2014

\title{
Effect of surface temperature on spreading rate of liquid droplet
}

\author{
Ksenia Batischeva ${ }^{a}$, Evgenija Orlova, and Dmitriy Feoktistov \\ National Research Tomsk Polytechnic University, 634050 Tomsk, Russia
}

\begin{abstract}
Experimental investigation of spreading rate variation of liquid droplet under the conditions of its free-falling on a heated surface has been executed. Effect of surface temperature of flexible copper substrate on spreading rate variation of liquid droplet under the conditions of its free-falling has been studied. It has been found that the curve of liquid drop spreading rate changes exponentially. The spreading rate after time point of $0,002 \mathrm{~s}$ assumes constant values $\mathrm{V}=0.3 \div 0.5 \mathrm{~m} / \mathrm{s}$ and does not depend on the surface temperature. Also it has been found that liquid drop spreading rate does not depend on the surface temperature at temperatures up to $108^{\circ} \mathrm{C}$. Continued heating results in an increased liquid drop spreading rate and reaches a maximum values at temperature of $140^{\circ} \mathrm{C}$. By heating the surface over $140^{\circ} \mathrm{C}$ the decreasing of spreading rate is occurred.
\end{abstract}

\section{Introduction}

Spreading of liquid drop on solid surface is the most important process when studying of wetting. Numerical and experimental investigations of liquid drop spreading on solid surface [1-4] have allowed to establish some important laws. However currently there is a lack of extended theory of wetting. There are no full published results of experimental studies of liquid drop spreading when it free-falls on a heated surface. It should be noted that investigation of mechanism of drops impingement with a heated substrate involves not only the determination of thermal processes, but also the physical and dynamic in particular spreading.

Cooling curves and similarity criteria have been obtained [2] under the conditions of drop falling on a heated substrate. The differences between profiles of large and small drops have been found. Motion of two related but independent components (central area and ring) of falling drop has been estimated experimentally [5]. Several stages of change of the droplet shape have been separated when it contacts with a surface [6]. On the first stage there is "flattening" of drop shape and drop acquires a shape close to the toroid. Further it is changed under the force of surface tension and acquires a shape of flattened hemispherical form with a certain contact diameter with a heating surface. Then, the process of evaporation from the surface and boiling in drop volume is happened.

The purpose of the work is defining spreading rate variation of liquid droplet under the conditions of its free-falling on a heated surface.

\footnotetext{
${ }^{a}$ Corresponding author: bka1801@mail.ru
} 


\section{Research technique}

A scheme of experimental setup is shown in Fig.1.

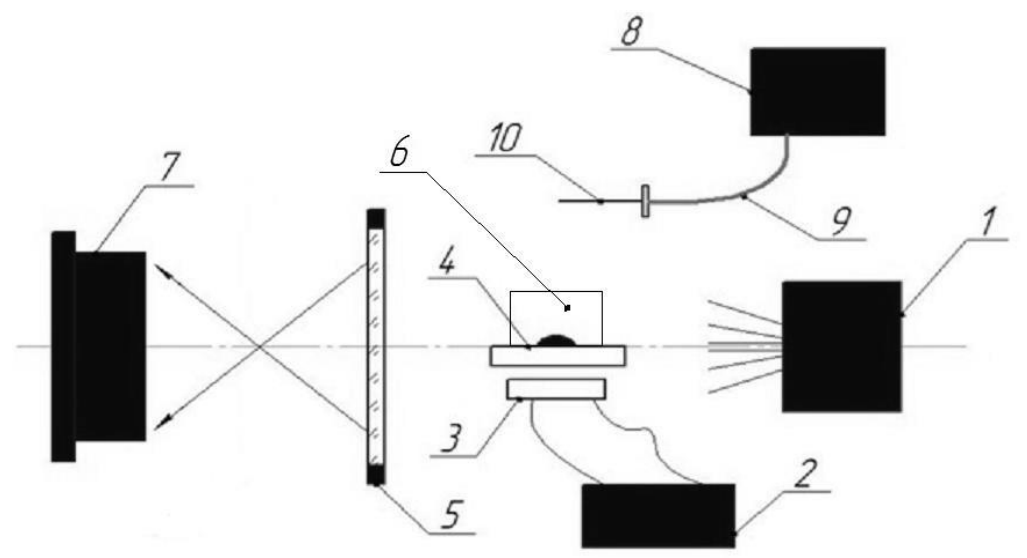

Figure 1. A scheme of experimental setup: 1 - light source, 2 - power unit of heating resistance, 3 - heating resistance, 4 - solid substrate, 5 - condensing lens, 6 - transparent box, 7 - high-speed camera, 8 - electronic unit pump, 9 - pipe of experimental liquid supply, 10 - dosing device.

The main elements of experimental setup are light source 1 , condensing lens 5 , high-speed camera 7 and testing area, which consists of solid substrate 4 and transparent box 6 .

Power unit 2 is connected to the heating resistance 3. The rate of water supply through pipe 9 to dosing device 10 is controlled by electronic unit pump (Cole-Parmer Touch Screen) 8. The dosing device is the needle ISO 7864-2011. The light flux passes through the droplet and enters a condensing lens 5 , where it refracts and detects by the high-speed camera 7.

The transparent box 6 (Fig.2) made of glass is destined for reducing of the impact of environmental factors, such as a movement of air mass, differential temperature in the room. The opening from top is needed for unhindered drops free-falling, side openings are needed for path of parallel rays from the light source 1 to the camera lens 7 .

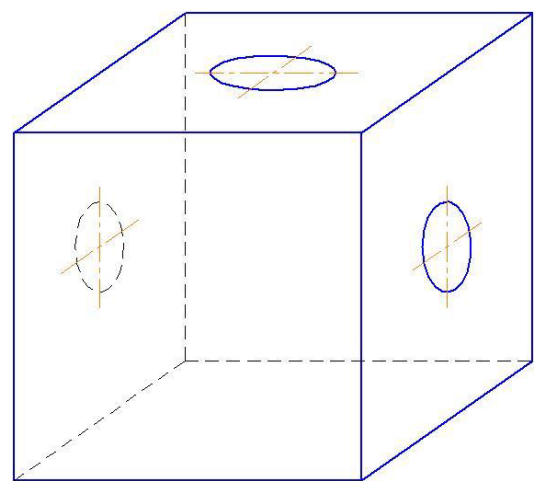

Figure 2. Model of transparent box.

Measuring of the temperature of the substrate was performed by eight-channel Agilent 34901A. The thermocouple "chromel-copel" (chemical compound: Nickel (Ni) - 44\%; iron (Fe) - 2\%; Copper $(\mathrm{Cu})-54 \%$ ) with measurement error $\pm 0.1^{\circ} \mathrm{C}$ was used as the temperature sensors. A scheme of arrangement of thermocouple on substrate is shown in Fig.3. 


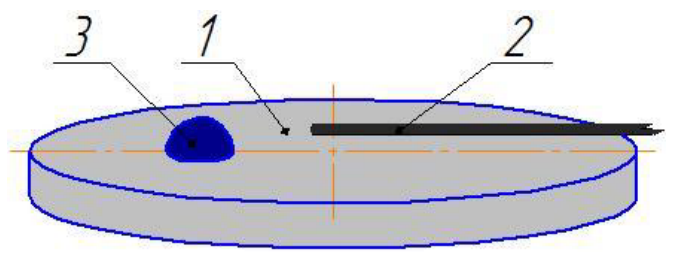

Figure 3. Arrangement of thermocouple: 1 - test substrate, 2 - thermocouple, 3 - sessile liquid drop.

As test substrate we use flexible copper disk of thickness $4 \mathrm{~mm}$ and diameter $54 \mathrm{~mm}$. Shadow method was used to record drop spreading process [7-9]. Drops of volume $6 \mu 1$ have been dosed to the surface from a height of $300 \mathrm{~mm}$. The range of temperature variation is $60-200{ }^{\circ} \mathrm{C}$. As a working liquid we use distilled non deaerated water.

The initial time point is the moment of contact free-falling drop with a heated surface. Video recording of this process has been held with a high-speed video camera FastCAMSA1.1 model 675KM1. Shooting speed of camera is 5000 frames per second at full-screen scanning $(1280 \times 1024$ resolution, 10 bit).

\section{Results and discussion}

Drop diameter has been registered according to spreading process on substrate. Spreading rate of liquid droplet we define as:

$$
V=\frac{D_{1}-D_{2}}{t}, \mathrm{~mm} / \mathrm{s},
$$

where $\mathrm{D}_{1}-$ drop diameter, $\mathrm{mm} ; \mathrm{D}_{2}-$ drop diameter recorded in the previous time step, $\mathrm{mm} ; \mathrm{t}=0.0002$ - time step, s.

Figure 3 demonstrates variation of liquid drop spreading rate in time.

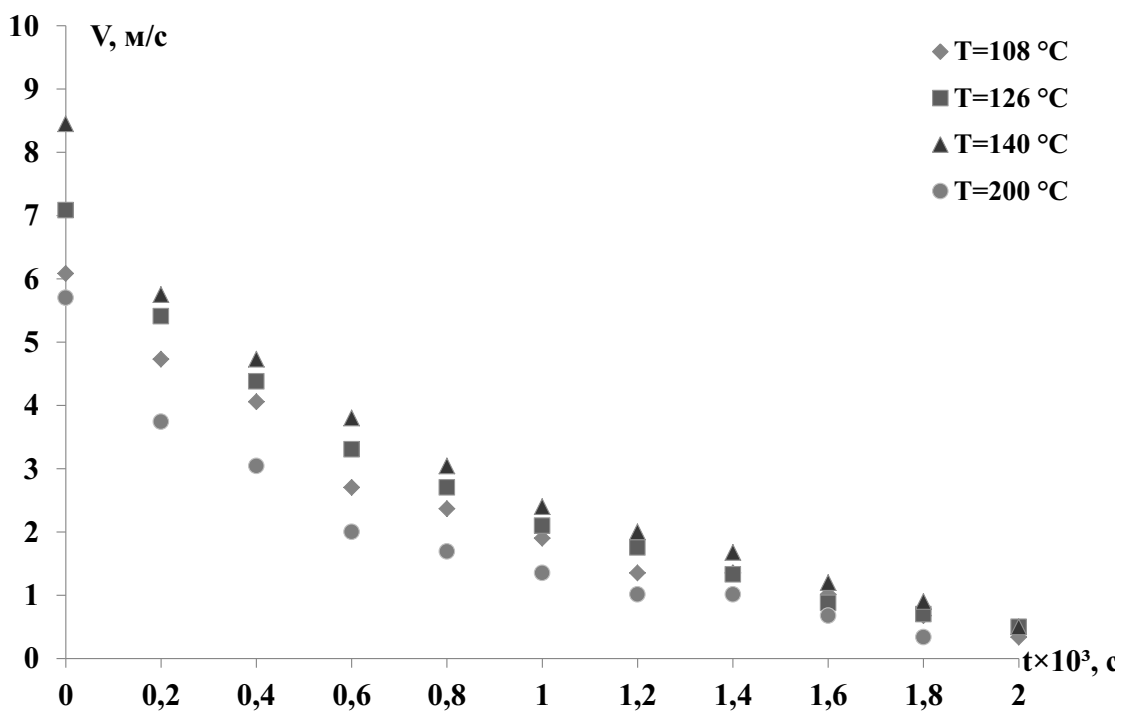

Figure 4. Liquid drop spreading rate at substrate temperatures $108^{\circ} \mathrm{C} ; 126^{\circ} \mathrm{C} ; 140^{\circ} \mathrm{C} ; 200^{\circ} \mathrm{C}$.

According to the analysis of Fig. 4 the curve of liquid drop spreading rate changes exponentially at range of temperature variation $60-200{ }^{\circ} \mathrm{C}$. At the initial time, when liquid drop contacts with the heated surface it spreads and contact diameter reaches maximum value under the force of inertia. Next, the attractive forces of the molecules contribute to its contraction to equilibrium. It should be 


\section{MATEC Web of Conferences}

noted that the spreading rate after time point $0,002 \mathrm{~s}$ assumes constant values $\mathrm{V}=0.3 \div 0.5 \mathrm{~m} / \mathrm{s}$ and does not depend on the surface temperature.

Also it has been found that liquid drop spreading rate does not depend on the surface temperature at temperatures up to $108^{\circ} \mathrm{C}$. Continued heating results in an increased liquid drop spreading rate and reaches a maximum values at temperature of $140^{\circ} \mathrm{C}$. By heating the surface over $140^{\circ} \mathrm{C}$ the decreasing of spreading rate is occurred.

These results can be used for predictive modeling of the processes occurring in the high-intensity heat exchangers, pneumatic, spray, rotary, drum, spiral dryer, in heat engines, in the schemes of inkjet printing, etc.

The work was realized within the research state assignment "Science" (Code of Federal Target Scientific and Technical Program 2.1410.2014).

\section{References}

[1] S.A. Borodin, Computer optics. 28, 66 (2005)

[2] N.N. Avakimyan, N.I. Vasiliev, V.V. Guguchkin, IV Minsk International Forum on Heat and Mass Transfer. 10, 315 (2000)

[3] A.V. Gulikov. Eksperimentalnoe i teoreticheskoe issledovanie protsessa soudareniya kapli zhidkosti s vyisokotemperaturnoy stenkoy: Ph.D. thesis in Engineering Science, - Moscow, 2007. $212 \mathrm{p}$.

[4] D. Bartolo, C. Josserand, D. Bonn, Phys. Rev. E. 62, 756 (2006)

[5] Meng-JiyWang, Fang-HsingLin, Yi-LinHung, Colloids Surf., A. 339, 224 (2009)

[6] P. S. Vasiliev, S. L. Reva, L. S. Reva, A. B. Golovanchikov, Volgograd State Technical University Izvestiia. 10, 13 (2012)

[7] V.Y. Gubarev, A.G. Arzamastcev, Thermal Processes in Engineering. 2, 63 (2010)

[8] E. Orlova, G. Kuznetsov and D. Feoktistov, EPJ Web of Conferences 76, 012039 (2014)

[9] E.Ya. Gatapova, A.A. Semenov, D.V. Zaitsev, O.A. Kabov, Colloid Surface A 441, 776 (2014) 